\title{
Chemiluminescence Sensing of Fluoride lons Using a Self-Immolative Amplifier
}

\author{
Ilke Simsek Turan ${ }^{\dagger}$ and Engin U. Akkaya* ${ }^{\dagger}, \ddagger$ \\ ${ }^{\dagger}$ UNAM-National Nanotechnology Research Center and ${ }^{\ddagger}$ Department of Chemistry, Bilkent University, Ankara 06800, Turkey
}

Supporting Information

ABSTRACT: An enhanced chemiluminescence signal is obtained when electronically triggered dioxetane cleavage is initiated by fluoride-mediated deprotection of the silyl-protecting group, followed by self-immolation via 1,4-quinone-methide rearrangement. The reaction takes place even when the probe is trapped within a PMMA layer on top of a glass plate. In that arrangement, fluoride in aqueous solutions can be detected selectively at low micromolar concentrations.

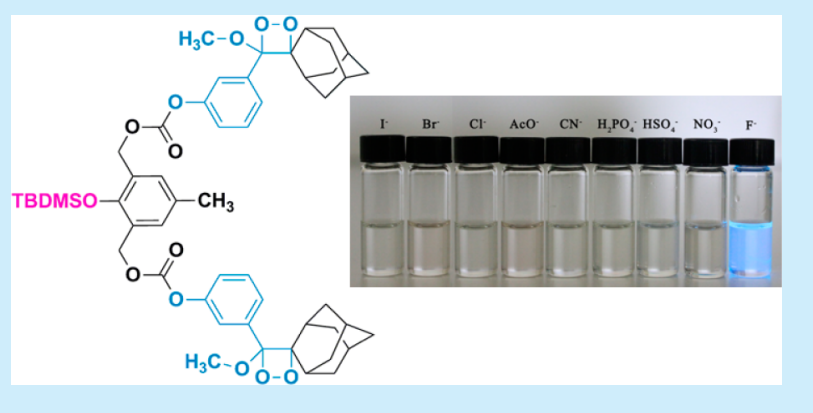

$\mathrm{O}$ ptical sensing of fluoride ions, especially in aqueous solutions, is very challenging because of their highly efficient hydration, reducing effective nucleophilicity and basicity. On the other hand, considering its presence in water and commercial products and its implication in a number of health problems, monitoring of fluoride concentration is an important public priority. ${ }^{1}$ At present, ion-selective electrodes are an option, ${ }^{2}$ but low-cost and straightforward assessment of fluoride ions require other methodologies. There have been many proposals for detection of fluoride by using chromogenic and fluorogenic probes, ${ }^{3}$ some working in organic solvents, and others operating in aqueous mixtures, all with acknowledged limitations such as low affinity, inhibition of response by water, limited spectral changes, or lack of selectivity.

As a chemiluminogenic unit, our choice was a stable 1,2dioxetane. 1,2-Dioxetanes are four-membered cyclic peroxides usually implicated as reactive intermediates in bioluminescence as well as hydrogen peroxide triggered chemiluminescence of oxalate derivatives. 1,2-Dioxatenes can be stabilized by the incorporation of bulky groups, including adamantyl or fenchyl substitutions. ${ }^{4}$ 3-Hydroxyphenyl substituent was shown ${ }^{5}$ to function as an electronic trigger; on deprotonation (phenoxide formation) 1,2-dioxetane ring is cleaved, generating the electronically excited ester product and eventually relaxing radiatively with a peak emission at $466 \mathrm{~nm}$. The process is known as chemically initiated electron exchange luminescence (CIEEL). There have been previous examples of chemiluminogenic agents that rely on silyl deprotection by fluoride, ${ }^{6}$ but in all cases, a single fluoride ion triggers decomposition of a single substituted dioxetane.

Self-immolation, on the other hand, refers to a very interesting chemical conversion typically resulting in complete fragmentation of large (even polymeric) molecules. ${ }^{7}$ Recently, Shabat and co-workers introduced a series of self-immolative linkers, ${ }^{3 j, 8}$ which when used judiciously, lead to valuable signal amplification in chemosensors targeting reactive analytes.
In this work, we wanted to incorporate a self-immolative linker to trigger two chemiluminescence processes at the same time, in response to single fluoride mediated deprotection event. The target molecule was synthesized (Scheme 1) in a few steps from commercially available materials, some in close analogy to the literature procedures. To that end, enhanced 3hydroxybenzaldehyde was reacted with benzoyl chloride, and the resulting phenyl ester was then converted to adamantyl-3hydroxyphenyl alkene derivative 4 . The self-immolative linker was prepared according Shabat and co-workers. Thus, compound 7 was obtained with silyl protection (TBDMS) already in place. Chemiluminogenic units were assembled by the reaction of activated linker with the 3-hydroxyphenyl moiety of the reporter unit (operation of the fluoride sensor is shown in Scheme 2). In the final step, the electron-rich enol ether is efficiently photooxygenated to yield 1,2-dioxetane 9 .

The 1,2-dioxetane derivative 9 obtained this way is thermally stable and can be stored under ambient conditions. We initially tested its response to fluoride anions in DMSO. Very bright blue chemiluminescence is triggered on addition of tetrabutylammonium fluoride (TBAF). Larger concentrations progressively led to more intense luminescence (Figure 1). We also wanted to demonstrate the selective nature of the chemiluminescene signal. Treatment with a number of potential competitor anions resulted in very little luminescence or none at all (Figure 2). The detection limits were calculated (Supporting Information, S11-S14) and determined to be 47 $\mu \mathrm{M}$ in DMSO and $0.67 \mathrm{mM}$ in DMSO/aqueous buffer mixture (90/10, pH 7.2).

The silyl protection group is stable in DMSO-aqueous buffer solutions at moderately acidic solutions (e.g., at $\mathrm{pH} 4.0$ ).

Received: February 1, 2014

Published: March 7, 2014 
Scheme 1. Synthesis of the Self-Immolative

Chemiluminogenic Fluoride Sensor
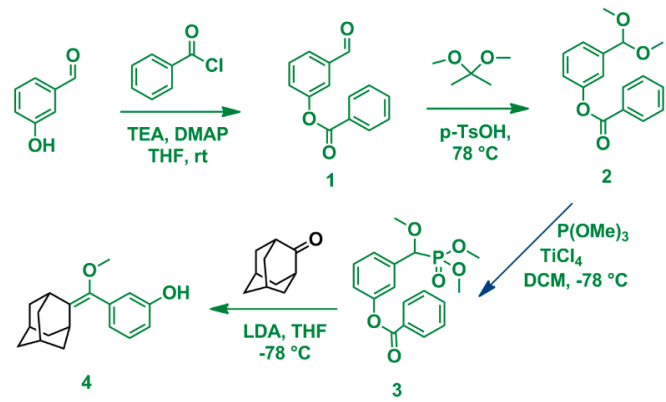

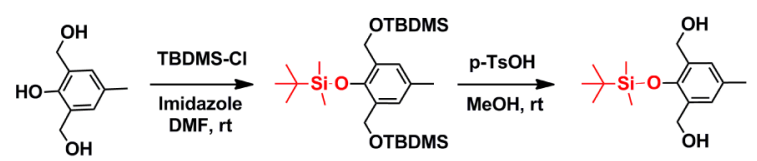

5

6

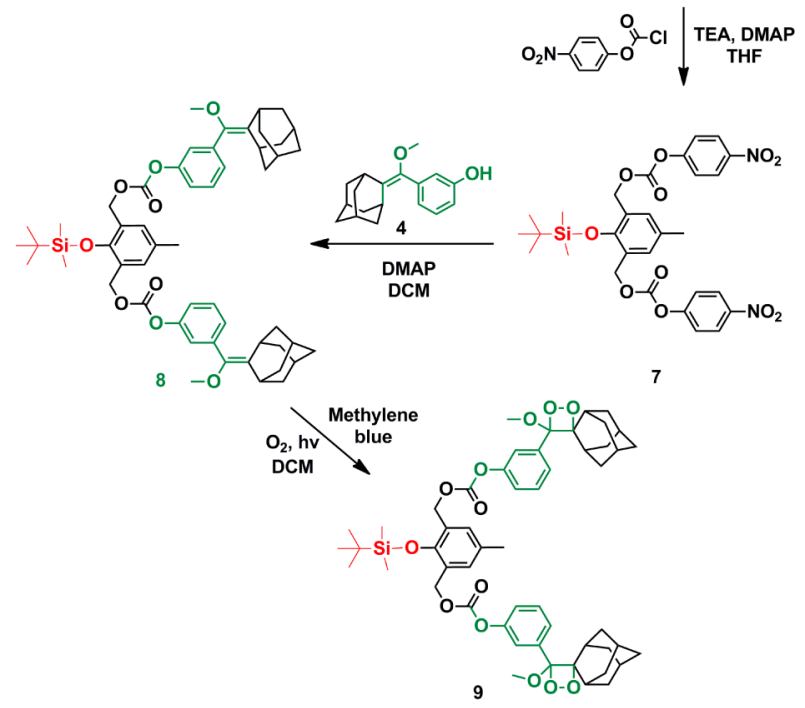

Scheme 2. Self-immolation mechanism and multivalent response

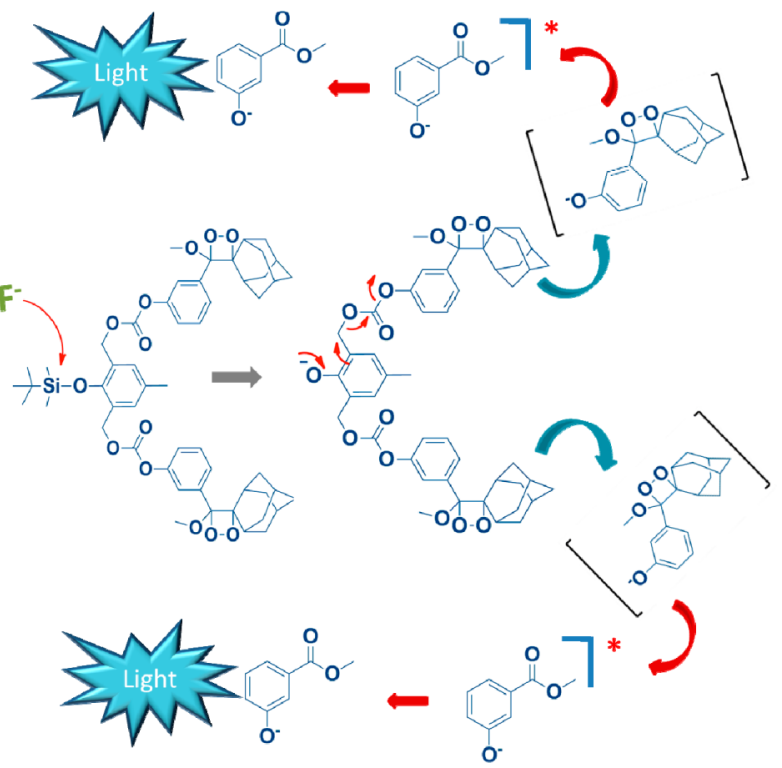

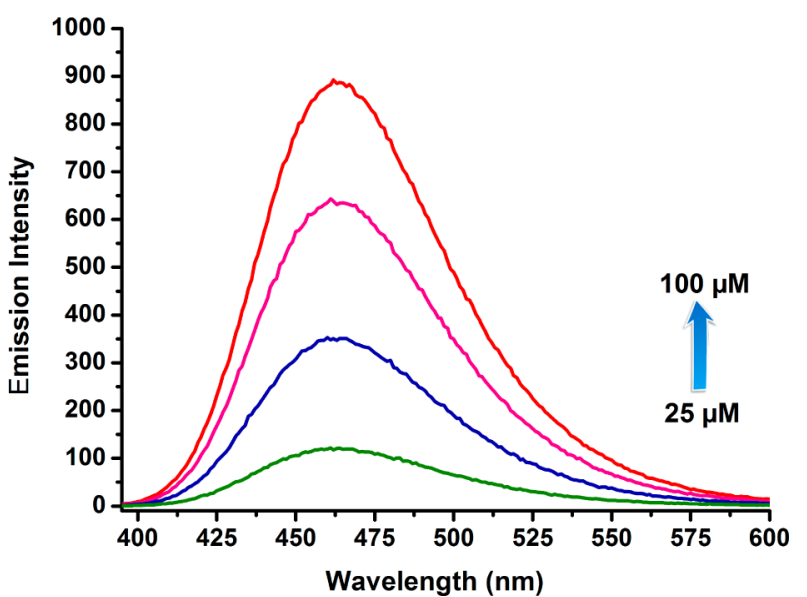

Figure 1. Chemiluminescence spectra of $9+\mathrm{F}^{-}$in the presence of increasing $\mathrm{F}^{-}$concentrations. Probe concentration is $100 \mu \mathrm{M}$ in DMSO.

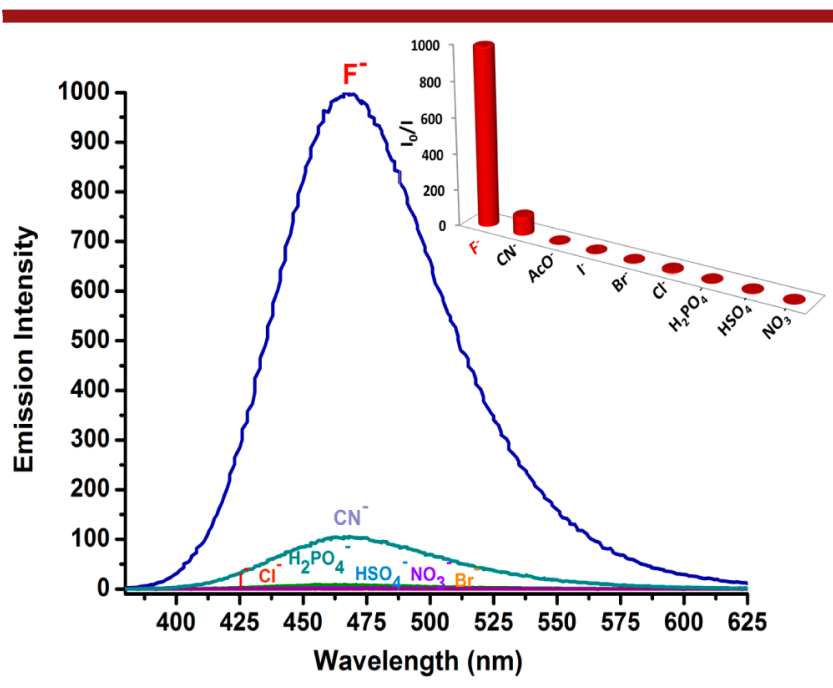

Figure 2. Selectivity of chemiluminogenic response. $\mathrm{CN}^{-}$in the form of tetrabutylammonium cyanide elicits very little response. All other anions tested generated no response in DMSO/PBS buffer (90/10, $\mathrm{pH}$ 7.2) Probe 9 concentration is $500 \mu \mathrm{M}$.

Digital photographs of the solutions (Figure 3) show the selectivity of chemiluminescence under ambient light. Fluoride

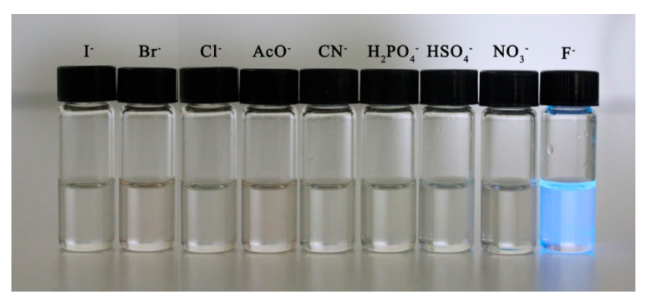

Figure 3. Selective chemiluminescent response of the fluoride probe 9 under ambient light.

in DMSO or DMSO-buffer mixture elicits a clear response with luminescence intensity reflecting fluoride concentration. Chemiluminescence quantum yield was determined $\left(\phi_{\mathrm{CL}}=\right.$ 0.46 ), and to our delight, it is almost twice that of the single chemiluminescent 1,2-dioxetane unit. Thus, amplification through the use of self-immolative linker was validated. 
We also wanted to demonstrate the response to aqueous fluoride solution in the form of test strips. To that end, we impregnated PMMA with the chemiluminogen probe 9. The polymer strips on glass were prepared. When these probes are dipped into fluoride solutions in THF chemiluminescence is triggered. Again, the luminescence intensity is related to the fluoride concentration in solution (Figure 4). The photograph

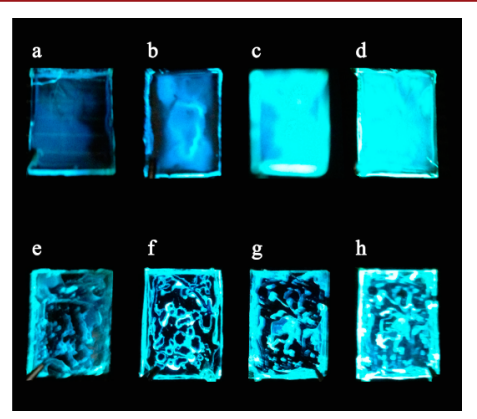

Figure 4. PMMA on glass impregnated with probe 9, exposed to increasing concentrations of $\mathrm{F}^{-}(12.5 \mathrm{mM}$ to $100 \mathrm{mM})$ in THF (top, a-d). Same strips exposed to $250 \mathrm{mM}$ fluoride in varying percentages of DMSO buffer (PBS, pH 7.2) solvent mixture (e-h, 40, 30, 20, $10 \%)$.

was digitized, and the brightness of the strips was quantified. The plot of brightness as a function of fluoride concentration shows a reproducible relation. The effect of water content was also investigated by varying the percentage of buffer in DMSO. Because of the thickness of the polymeric layers and inhomogeneity of diffusion of fluoride (Figure 4), the polymer strips shows bright and dark patches except for the high fluoride case, but the integrated luminescence data (Figure 5) for the chemiluminescence triggered on the strips provides usable analytical data.

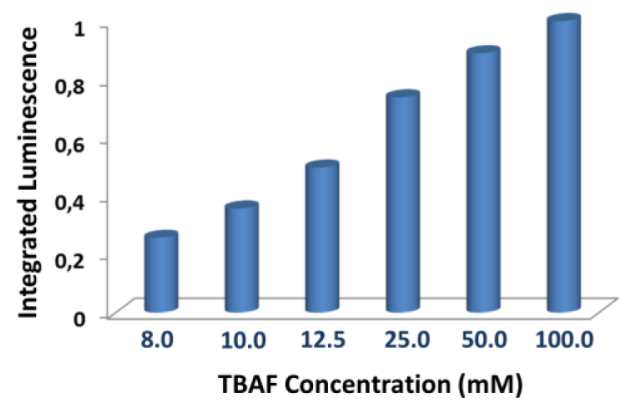

Figure 5. Integrated luminescence from the PMMA strips showing the response to increasing fluoride concentrations in THF.

In conclusion, we demonstrated that multiple chemiluminescence events can be triggered through use of a selfimmolative linker. This approach offers a chemical avenue for enhancing the signal produced in response to a given analyte. Considering the fact that chemiluminescence in principle can provide a rapid, qualitative, and/or quantitative test for analytes of interest, we are confident that other probes combining the power of self-immolation and chemiluminescence will emerge. Rapid assessment of fluoride concentrations in drinking water could be a possible application, and the bright chemiluminescence of the probe 9 or structurally related derivatives could provide a promising alternative to current methods.

\section{ASSOCIATED CONTENT}

\section{Supporting Information}

Methods, experimental procedures, and additional spectral data. This material is available free of charge via the Internet at http://pubs.acs.org.

\section{AUTHOR INFORMATION}

\section{Corresponding Author}

*E-mail: eua@fen.bilkent.edu.tr.

Notes

The authors declare no competing financial interest.

\section{ACKNOWLEDGMENTS}

We gratefully acknowledge support from TUBITAK in the form of a scholarship to IST.

\section{REFERENCES}

(1) (a) Farley, J. R.; Wergedal, J. E.; Baylink, D. J. Science 1983, 222, 330-332. (b) Yang, Z.; Zhang, K.; Gong, F.; Li, S.; Chen, J.; Ma, J. S.; Sobenina, L. N.; Mikhaleva, A. I.; Yang, G.; Trofimov, B. A. Beilstein J. Org. Chem. 2011, 7, 46-52. (c) Horowitz, H. S. J. Public Health Dent. 2003, 63, 3-8. (d) Kleerekoper, M. Endocrinol. Metab. Clin. North Am. 1998, 27, 441-452. (e) Lennon, M. A. Bull. W. H. O. 2006, 84, 759760.

(2) (a) Van den Hoop, M. A. G.T.; Cleven, R. F. M. J.; van Staden, J. J.; Neele, J. J. Chromatogr. 1996, 739, 241-248. (b) Arancibia, J. A.; Rullo, A.; Olivieri, A. C.; Di Nezio, S.; Pistonesi, M.; Lista, A.; Band, B. S. F. Anal. Chim. Acta 2004, 512, 157-163. (c) Breadmore, M. C.; Palmer, A. S.; Curran, M.; Macka, M.; Avdalovic, N.; Haddad, P. R. Anal. Chem. 2002, 74, 2112-2118. (d) Hutchinson, J. J.; Evenhius, C. J.; Johns, C.; Kazarian, A. A.; Breadmore, M. C.; Macka, M.; Hilder, E. F.; Guijt, R. M.; Dicinoski, G. W.; Haddad, P. R. Anal. Chem. 2007, 79, 7005-7013. (e) Neal, M.; Neal, C.; Wickham, H.; Harman, S. Hydrol. Earth Syst. Sci. 2007, 11, 294-300.

(3) (a) Turan, I. S.; Cakmak, F. P.; Sozmen, F. Tetrahedron Lett. 2014, 55, 456-459. (b) Bozdemir, O. A.; Sozmen, F.; Buyukcakir, O.; Guliyev, R.; Cakmak, Y.; Akkaya, E. U. Org. Lett. 2010, 12, 14001403. (c) Ke, B.; Chen, W.; Ni, N.; Cheng, Y.; Dai, C.; Dinh, H.; Wang, B. Chem. Commun. 2013, 49, 2494-2496. (d) Kim, Y.; Gabbai, F. P. J. Am. Chem. Soc. 2009, 131, 3363-3369. (e) Swamy, K. M. K.; Lee, Y. J.; Lee, H. N.; Chun, J.; Kim, Y.; Kim, S.-J.; Yoon, J. J. Org. Chem. 2006, 71, 8626-8628. (f) Cao, X.; Lin, W.; Yu, Q.; Wang, J. Org. Lett. 2011, 13, 6098-6101. (g) Jo, M.; Lim, J.; Miljanić, O. Š. Org. Lett. 2013, 15, 3518-3521. (h) Kim, S. Y.; Hong, J.-I. Org. Lett. 2007, 9, 3109-3112. (i) Kim, H. J.; Kim, S. K.; Lee, J. Y.; Kim, J. S. J. Org. Chem. 2006, 71, 6611-6614. (j) Feigenbaum-Perry, R.; Sella, E.; Shabat, D. Chem.-Eur. J. 2011, 17, 12123-12128.

(4) (a) Ciscato, L. F. M. L.; Weiss, D.; Beckert, R.; Baader, W. J. Photochem. Photobiol. A 2011, 218, 41-47. (b) Ciscato, L. F. M. L.; Bartoloni, F. H.; Weiss, D.; Beckert, R.; Baader, W. J. J. Org. Chem. 2010, 75, 6574-6580. (c) Ciscato, L. F. M. L.; Weiss, D.; Beckert, R.; Bastos, E. L.; Bartoloni, F. H.; Baader, W. J. New J. Chem. 2010, 75, 6574-6580. (d) Schaap, A. P.; Sandison, M. D.; Handley, R. S. Tetrahedron Lett. 1987, 28, 1159-1162. (e) Richard, J.-A.; Jean, L.; Romieu, A.; Massonneau, M.; Noack-Fraissignes, P.; Renard, P.-Y. Org. Lett. 2007, 9, 4853-4855. (f) Richard, J.-A.; Jean, L.; Schenkels, C.; Massonneau, M.; Romieu, A.; Renard, P.-Y. Org. Biomol. Chem. 2009, 7, 2941-2957. (g) Di Fusco, M.; Quintavalla, A.; Trombini, C.; Lombardo, M.; Roda, A.; Gurdigli, M.; Mirasoli, M. J. Org. Chem. 2013, 78, 11238-11246.

(5) (a) Matsumoto, M. J. Photochem. Photobiol. C 2004, 5, 27-53. (b) Sabelle, S.; Renard, P.-Y.; Pecorella, K.; de Suzzoni-Dezard, S.; Creminon, C.; Grassi, J.; Mioskowski, C. J. Am. Chem. Soc. 2002, 124, 4874-4880. (c) Augusto, F. A.; de Souza, G. A.; de Souza, S. P.; Khalid, M.; Baader, W. J. Photochem. Photobiol. 2013, 89, 1299-1317. 
(d) Adam, W.; Bronstein, I.; Trofimov, A. V. J. Phys. Chem. A 1998, 102, 5406-5414.

(6) (a) Watanabe, N.; Nagashima, Y.; Yamazaki, T.; Matsumoto, M. Tetrahedron 2003, 59, 4811-4819. (b) Hoshiya, N.; Fukuda, N.; Maeda, H.; Watanabe, N.; Matsumoto, M. Tetrahedron 2006, 62, 5808-5820. (c) Nery, A. L. P.; Röpke, S.; Calalani, L. H.; Baader, W. J. Tetrahedron Lett. 1999, 40, 2443-2446. (d) Shamsipur, M.; Chaichi, M. J. Luminescence 2002, 17, 299-304. (e) Matsumoto, M.; Mizuno, T.; Watanabe, N. Chem. Commun. 2003, 482-483. (f) Adam, W.; Trofimov, A. V. J. Org. Chem. 2000, 65, 6474-6478. (g) Schaap, A. P.; Chen, T.-S.; Handley, R. S.; DeSilva, R.; Giri, B. P. Tetrahedron Lett. 1987, 28, 1155-1158.

(7) (a) Avital-Shmilovici, M.; Shabat, D. Soft Matter 2010, 6, 10731080. (b) Sagi, A.; Weinstein, R.; Karton, N.; Shabat, D. J. Am. Chem. Soc. 2008, 130, 5434-5435. (c) Wang, W.; Alexander, C. Angew. Chem., Int. Ed. 2008, 47, 7804-7806. (d) Chen, E. K.Y.; McBridge, R. A.; Gillies, E. R. Macromolecules 2012, 4, 7364-7374.

(8) (a) Sella, E.; Klafter, L. J.; Shabat, D. J. Am. Chem. Soc. 2010, 132, 3945-3952. (b) Sella, E.; Shabat, D. J. Am. Chem. Soc. 2009, 131, 9934-9936. (c) Sella, E.; Shabat, D. Chem. Commun. 2008, 57015703. (d) Danieli, E.; Shabat, D. Bioorg. Med. Chem. 2007, 15, 73187324. (f) Gu, J.-A.; Lin, Y.-J.; Chia, Y.-M.; Lin, H.-Y.; Huang, S.-T. Microchim. Acta 2013, 180, 801-806. (g) Baker, M. S.; Philips, S. T. J. Am. Chem. Soc. 2011, 133, 5170-5173. 